\title{
Regional Analgesia in Acute Pain Management in Orthopaedic Trauma Patients
}

\author{
Aamir Siddiqui* \\ Department of Critical Care Medicine, Egypt \\ *Corresponding author: Aamir Siddiqui, Department of Critical Care Medicine, Kasr Al ainy St, Cairo 11562, Egypt
}

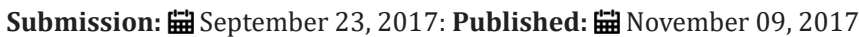

Abbreviations: AAOS: American Academy of Orthopedic Surgeons; EAST: Eastern Association for the Surgery of Trauma; WHO: World Health Organization; LOS: Length of Stay

\section{Editorial}

In recent years, there has been dramatic increase in attention towards quality and patient's satisfaction, during hospital care. And pain, as leading complains in acute trauma patients, its ineffective management has been identified to have an adverse effect on patient's satisfaction, as well as on clinical outcomes [1]. For these reasons, regulatory agencies like American Academy of Orthopedic Surgeons (AAOS), Eastern Association for the Surgery of Trauma (EAST), World Health Organization (WHO) etc, have given great importance to the evaluation and treatment of acute pain [2]. During this same time, the number of reliable acute pain management strategies, techniques, and applications has also grown significantly.

Despite our greatest capacity to improve the treatment of acute pain and the increased awareness of the negative financial and physiologic consequences of inadequately treated acute pain, many patients continue to suffer from moderate, severe, or excruciating acute pain following trauma and surgery [3]. The World Organization (WHO) estimates that 5.5 billion people (83\% of the world's population) live in countries with low to non-existent access to controlled medicines and have inadequate access to treatment for moderate to severe pain [4]. Ineffective pain management has been associated with increased length of stay (LOS), delayed ambulation, long-term effects like functional impairment and emotional \& psychological distress [1-5].

Patients with orthopedic trauma comprise the full range and extremes of injury severity, age, and health status. It is well known fact that orthopedic injuries are among most pain full [3]. Despite being at comparatively increased risk for experiencing severe acute pain, unlike many elective surgeries, most of these patients have already experienced some degree of peripheral and central sensitization before surgical interventions, and may be at an increased risk of developing chronic pain because of an increased exposure to severe pain.

\section{Timeline of Acute Pain Management}

Traditional reliance on opioids for acute pain management has been a part of management for decades. Although opioids relieve pain in multiple areas of the body simultaneously, often helpful in trauma-related injury, they are not effective analgesics for sources of "dynamic" pain (precipitated with cough, ambulation etc) compared with other modalities [6-8]. Further, they do not mitigate central sensitization, a key determinant in the development of chronic pain [9]. Studies report patients with greater signs of post-traumatic psychological stress (those who scored higher for catastrophic thinking, anxiety, post-traumatic stress disorder, and depression) were significantly more likely $(\mathrm{p}<0.001)$ to be taking opioid pain medications 1-2 months after surgery, regardless of injury severity, fracture site, or treating surgeon. Their postsurgical disability severity magnitude was significantly higher $(\mathrm{p}<0.001)$ than patients not using opioids [10]. Additionally, the preference for alert mental status to fully evaluate the extent and severity of injury is often difficult to accomplish, and analgesia is often delayed due to priorities given to more life-threatening injuries or the need for serial neurologic or other provocative examinations. These all suggest for search of parallel acute pain management modalities besides conventional reliance to opioids.

Alternatives to high dose opioids, including the use of NSAIDs, such as ketotolac, and regional anaesthesia can be effective in reducing total IV opioids administration. Newer strategies, such as pre-emptive and multimodal analgesic techniques, have been demonstrated to have better analgesic effects, opioid-sparing (and associated adverse effects), decreased acuity of postoperative care, decreased length of stay, improved early range of motion, improved 
mobility and recovery, decreased persistent pain, and increased patient satisfaction $[11,12]$.

\section{Regional Analgesia}

In many centres, regional anaesthetic techniques (like neuroaxial analgesia, peripheral nerve blocks, and wound infiltration) are used extensively for pain management in the polytrauma patients. Regional analgesia can provide improved analgesia, improved outcomes, and lead to higher patient satisfaction [13]. Ideally, regional analgesiaby covering the entire phase of initial inflammatory response lasting days or perhaps weeks in the case of poly trauma, have shown to have added benefits, especially in chronic or long term effects like functional impairment \& psychological distress.

Many studies report, improved postoperative analgesia with fewer adverse side effects in comparison to opioids and other pain management modalities, with regional analgesia. Incidences of nausea and vomiting were found significantly lower when opioids used locally compared to intravenous forms [14]. Patients treated with regional analgesia also required less supplemental oxygen, and had less postoperative ileus resulting from minimizing opioid use and the sympathetectomy that accompanies epidural analgesia $[15,16]$. Peripheral nerve blocks were also found to decrease incidences of pruritus, urinary retention, hypotension, difficulty with ambulation, and respiratory depression [17].

Both epidural and peripheral nerve blocks have shown to decrease pain scores, increase of motion exercises, decreased hospital stay, and decrease rehabilitation time compared with intravenous patient controlled analgesia, although continued peripheral nerve block had fewer side effects compared with epidural analgesia [18,19]. And several trials and meta-analyses have shown improved inpatient satisfaction when regional analgesia was used [20,21]. Although regional analgesia offers many benefits, it also introduces risks. The major risks associated with regional analgesia are local anaesthetic toxicity (including devastating complications like seizures and/or cardiac arrest) and nerve injury [22]. Pneumothorax, phrenic nerve blockade, inadvertent epidural or subarachnoid spread, hematoma, and infections are other risks associated. These risks are largely been described in outpatient surgery population, and may be greater in critically ill patients [23] In addition, there has been concerns about regional analgesia over masking compartment syndrome, in polytrauma patients.

\section{Summary}

Regional and neuraxial anaesthesia have become increasingly popular as intra operative anaesthetic techniques in recent years, but when compared to general pain management modalities they are still not aggressively used. With provided add-on benefits which support endpoints of recovery, time to discharge, analgesia, patient satisfaction, and relatively low risk profile compared to conventional pain management protocols, it is suggestive that regional analgesia should be used more frequently as mainstream technique in acute pain management in orthopedic trauma patients.

\section{References}

1. Carr DB, Goudas LC (1999) Acute pain. Lancet London, England 353(9169): 2051-2058.

2. (2010) Australian and New Zealand College of Anesthetists. Statement on patients' rights to pain management and associated responsibilities (2010) PS45.

3. McGrath B, Elgendy H, Chung F, Kamming D, Curti B, et al. (2004) Thirty percent of patients have moderate to severe pain $24 \mathrm{hr}$ after ambulatory surgery: a survey of 5,703 patients. Can J Anaesth 51(9): 886-891.

4. Scholten W (2013) Access to Opioid Analgesics: Essential for Quality Cancer Care. In: Hanna M, Zylicz Z (Eds.), Cancer Pain. Springer, London, UK.

5. Gupta A, Lee LK, Mojica JJ, Nairizi A, George SJ (2014) Patient perception of pain care in the United States: a 5-year comparative analysis of hospital consumer assessment of health care providers and systems. Pain physician 17(5): 369-377.

6. Popping DM, Zahn PK, Van AHK, Dasch B, Boche R, et al. (2008) Effectiveness and safety of postoperative pain management: a survey of 18925 consecutive patients between 1998 and 2006 (2nd revision): a database analysis of prospectively raised data. Br J Anaesth 101(6): 832-840.

7. Ilfeld BM, Morey TE, Enneking FK (2002) Continuous infraclavicular brachial plexus block for postoperative pain control at home: a randomized, double-blinded, placebo-controlled study. Anesthesiology 96(6): 1297-1304.

8. Kehlet H (1994) Postoperative pain relief--what is the issue? Br J Anaesth 72(4): 375-378.

9. Berube M, Choiniere M, Laflamme YG, Gelinas C (2016) Acute to chronic pain transition in extremity trauma: A narrative review for future preventive interventions (part 1). Int J Orthop Trauma Nurs 23: 47-59.

10. Helmerhorst GT, Vranceanu AM, Vrahas M, Smith M, Ring D (2014) Risk factors for continued opioid use one to two months after surgery for musculoskeletal trauma. J Bone Joint Surg Am 96(6): 495-499.

11. Fabi DW (2016) Multimodal Analgesia in the Hip Fracture Patient. J Orthop Trauma 30 (Suppl 1): S6-S11.

12. Singelyn FJ, Ferrant T, Malisse MF, Joris D (2005) Effects of intravenous patient-controlled analgesia with morphine, continuous epidural analgesia, and continuous femoral nerve sheath block on rehabilitation after unilateral total-hip arthroplasty. Reg Anesth Pain Med 30(5): 452457.

13. Schulz SS, Boezaart A, Hata JS (2005) Regional analgesia in the critically ill. Crit Care Med 33(6): 1400-1407.

14. Salomäki TE, Laitinen JO, Nuutinen LS (1991) A randomized doubleblind comparison of epidural versus intravenous fentanyl infusion for analgesia after thoracotomy. Anesthesiology 75(5): 790-795.

15. Liu SS, Wu CL (2007) Effect of postoperative analgesia on major postoperative complications: a systematic update of the evidence. Anesth Analg 104(3): 689-702.

16. Ford RP GJ, Rich R, et al. (2001) An evaluation of immediate recovery after regional and general anesthesia: A two-year review of 801 ambulatory patients undergoing hand surgery. Regional anesthesia and pain medicine 26(Suppl): 42.

17. Grass J (1993) Surgical outcome: regional anesthesia and analgesia versus general anesthesia. Anesthesia Review 20: 117-125.

18. Capdevila X, Barthelet Y, Biboulet P, Ryckwaert Y, Rubenovitch J, et al. (1999) Effects of preoperative analgesic technique on the surgical outcome and duration of rehabilitation after major knee surgery. Anesthesiology 91(1): 8-15. 
19. Singelyn FJ, Gouverneur JM (1999) Postoperative analgesia after total hip arthroplasty: i.v. PCA with morphine, patient-controlled epidural analgesia, or continuous 3-in-1 block? a prospective evaluation by our acute pain service in more than 1,300 patients. J Clin Anesth 11(7): 550554.

20. Borgeat MDA, Perschak MDH, Bird MDP, Hodler MDJ, Gerber MDC (2000) Patient-controlled Inter scalene Analgesia with Ropivacaine $0.2 \%$ Versus Patient-controlled Intravenous Analgesia after Major Shoulder Surgery Effects on Diaphragmatic and Respiratory Function Anesthesiology 92(1):102-108.
21. Wu CL, Naqibuddin M, Fleisher LA (2001) Measurement of patient satisfaction as an outcome of regional anesthesia and analgesia: a systematic review. Reg Anesth Pain Med 26(3): 196-208.

22. Auroy Y, Benhamou D, Bargues L, Ecoffey C, Falissard B, et al. (2002) Major complications of regional anesthesia in France: The SOS Regional Anesthesia Hotline Service. Anesthesiology 97(5): 1274-1280.

23. Greensmith JE, Murray WB (2006) Complications of regional anesthesia. Current opinion in anesthesiology 19(5): 531-537. 